\title{
Editorial
}

\section{La dimensión fundante de las prácticas de investigación}

\author{
Nieto Fernández, Enrique \\ Universidad de Alicante, Dpto. de Expresión Gráfica y Cartografía, enrique.nieto@ua.es \\ Director [i2]
}

Parece que últimamente investigar en arquitectura consiste en acomodar lo que hacemos a los modos de la nueva universidad. De acuerdo, es cierto que no es tan nueva, pero sí es muy reciente nuestra plena incorporación al mundo universitario. Asentados en las históricas escuelas politécnicas, nuestros modos de estar eran muy diferentes. Ahora intentamos ser otros, sin que por su parte muestren gran interés por algunas de nuestras más preciadas características.

El origen de [i2] hay que situarlo en este esfuerzo por aproximarnos a unas producciones científicas que fueron diseñadas para otros campos disciplinares y a través de unos protocolos que ahora nos llegan muy reconstruido por las ansiedades de las economías neoliberales anglosajonas. En este sentido, nos cuesta por ejemplo asimilar la ausencia de economías que soporten estos esfuerzos, o la perversión con que éstas aparecen en los casos más extremos. En nuestro caso, asistimos perplejos a la inagotable generosidad con que autorxs y revisorxs responden a nuestras demandas, a cuenta de beneficios futuros de improbable verificación. También reflexionamos sobre la estrechez de los formatos propuestos por las revistas científicas, que de modo tan particular segregan lo que es producción del conocimiento de lo que es su divulgación, el texto. En nuestras prácticas esto nunca fue así. $\mathrm{O}$ al menos tan así.

Pero hay algunas cuestiones sobre las que sí estamos convencidxs. Una de ellas tiene que ver con la necesidad de imbricar nuestras investigaciones en las pertinencias del presente. Es urgente pensar en la dimensión contemporánea de lo que hacemos. Es cuestión de responsabilidad. Nos gusta pensar que lo que hacemos incide y se relaciona con lo que está pasando ahora. Nos gusta imaginarnos como activistas del presente a partir de unos instrumentales específicos. No queremos renunciar a sentirnos partícipes en la producción de futuros más deseables junto con otros muchos agentes, unidos en comunidades de pensamiento-acción. En un mundo como el actual, caracterizado por un aumento de la reflexividad, por una transversalidad de los asuntos y por unas urgencias cada vez más compartidas, la investigación universitaria debe establecer compromisos precisos con la realidad. Al menos la universidad pública.

Otra cuestión que nos preocupa apunta a la dimensión fundante de las prácticas de investigación. Se trataría de concentrarnos no tanto en los resultados que unos métodos abstractos producen, sino en los espacios que se abren en el seno de lo que hacemos, lo que atañe a 
quiénes nos juntamos, a cómo estamos juntxs y a como las prácticas convocan a otrxs. En un mundo amenazado por la destrucción sistemática de nuestros tejidos próximos, estamos llamados a comprometernos con la redescripción constante de estas maneras alternativas de trabajar para resistir a la barbarie que viene. En esta línea se alinean pensadoras tan dispares como Isabelle Stengers, Karen Barad o Marina Garcés, desde una mirada atenta al mundo como espacio de vida y convivencia entre los seres humanos y los mucho más que humanos. Atender al mundo en que vivimos y no tanto al devenir maquínico que nos proponen los órganos de vigilancia de la investigación académica implica algunas transformaciones importantes, como serían la redescripción en términos más justos de la evaluación o incluso de nuestra convivencia en el seno de una institución como la universidad, tan proclive a homogeneizar experiencias y protocolos.

La pregunta por la investigación es también una pregunta por la institución universitaria. Evidentemente no es la Universidad el único lugar donde se produce conocimiento, pero sí se trata de un laboratorio particular seriamente amenazado por los excesos del capitalismo neoliberal y por unas dificultades endémicas de la universidad y de las escuelas de arquitectura para repensarse en contextos siempre cambiantes. Autoras como las citadas nos invitan imaginar un tipo de resistencia que arranca desdes posiciones tan próximas como las que ocurren entre nosotrxs, ya que es ahí precisamente donde el mundo se coproduce con toda su virulencia.

La universidad es quizás la institución más representativa de la propuesta epistemológica derivada de la Ilustración. La investigación universitaria constituye la enactación concreta del imperativo ilustrado por conocer más y mejor. Es el lugar donde este mandato aparece naturalizado. Sin embargo, hoy en día cabe preguntarse si la obsesión por conocer sigue siendo tan relevante como antaño, si sigue siendo útil ampliar los límites del conocimiento humano, o incluso si es todavía viable el proyecto de conocer exclusivamente a través de la razón instrumental. Estas preguntas son sin duda incómodas y el interés por la dimensión fundante de las prácticas conseguiría desplazar estas dudas razonables para permitirnos pensar más afirmativamente sobre aquello en lo que estamos. También es cierto que preocuparse por las prácticas implica de algún modo despreocuparse de la institución. Las horas son las que son. Creo que son otros los lugares de acción. También está implícita en estas líneas la duda sobre si puede ser la investigación un recorte de la realidad, un espacio de excepción. Y si podemos seguir reclamando la universidad como un lugar sin condiciones. En su momento me pareció arrebatadora la propuesta de Derrida, pero han pasado demasiadas cosas estos años. Hoy en día aquellos afanes autonomistas ya no constituyen un horizonte esperanzador.

Porqué, al fin y al cabo, ¿para qué mundos investigamos? Esta pregunta nos aboca a una conversación en torno a las éticas que dan forma a nuestras prácticas. Nos permiten establecer unas relaciones entre fines y medios que escapan a las estrechas lógicas de la ANECA o la CNEAI. Las éticas ecológicas o las éticas de las diferencias nos proponen ya desde hace tiempo direcciones de trabajo que interpelan directamente a los modos de relacionarnos con la alteridad. Pero esto daría lugar a otra conversación. 